\title{
Crosniera wennerae, a new species of thalassinidean (Crustacea: Decapoda: Thomassiniidae) from the South Atlantic Bight
}

\author{
RICHARD W. HEARD ${ }^{1} \&$ RACHAEL A. KING ${ }^{2}$ \\ ${ }^{1}$ Department of Coastal Sciences, University of Southern Mississippi, Gulf Coast Research Laboratory, Campus Ocean Springs, MS \\ 39566-7000, USA. E-mail: richard.heard@usm.edu \\ ${ }^{2}$ Southeastern Regional Taxonomic Center, South Carolina Department of Natural Resources, Charleston, South Carolina, 29422- \\ 2559.E-mail:KingR@dnr.sc.gov
}

\begin{abstract}
Crosniera wennerae sp. nov. is described from a depth of $318 \mathrm{~m}$ in the South Atlantic Bight off North Carolina, USA. The species, based on a female specimen $20 \mathrm{~mm}$ in length, is distinguished from the other four nominal species of the genus by a combination of characters, including smooth uropodal lateral margins, well-developed exopods on maxillipeds 2 and 3, the smooth inner margin of the merus of maxilliped 3, and the presence of long, simple setae on the uropods, telson, and posterior margin of sixth abdominal somite. Crosniera wennerae sp. nov. represents the second member of the genus described from the western Atlantic. A key is presented for the separation of the species of Crosniera.
\end{abstract}

Key words: Thalassinidea, Thomassiniidae, Crosniera, wennerae, South Atlantic Bight

\section{Introduction}

During an examination of thalassinidean material from the South Atlantic Bight (United States east coast between Cape Hatteras, NC and Cape Canaveral, FL) housed in the collections of the National Museum of Natural History (Smithsonian Institution), a new species belonging to the thalassinidean genus Crosniera Kensley and Heard, 1991 was discovered. This species is described and illustrated here.

Crosniera belongs within the family Thomassinidae, originally established by de Saint Laurent (1979) as a subfamily (Thomassiniinae) on the basis of a single species, Thomassinia gebioides de Saint Laurent, 1979 (Kensley and Heard, 1991; Poore, 1997). Manning and Felder (1991) suggested the elevation of Thomassiniinae to family rank for Callianassa minima Rathbun 1901 and later Poore (1994) firmly established it in his phylogenetic examination of the Thalassinidea. In their examination of the Callianideidae, Kensley and Heard (1991) reestablished two monotypic genera that were later added to the Thomasiniidae, Crosniera and Mictaxius, with Callianassa minima, and Mictaxius thalassicola Kensley and Heard, 1991, respectively, as their type species. At present Thomassina de Saint Laurent, 1979 and Mictaxius Kensley and Heard, 1991 each contain two species (see Poore, 1997; Ngoc-Ho, 2005). The genus Crosniera presently contains four nominal species (C. minima (Rathbun 1901) from the western Atlantic, C. corindon Poore, 1997, C. panie Poore, 1997, and C. dayrati Ngoc-Ho, 2005 from the southwestern Pacific). Poore (1997) noted two further possible species (from Indonesia and the Gulf of California) based on two specimens in poor condition, but these have never been formally described. 


\section{Material and methods}

The material was collected by personnel of Texas Instruments using a box core aboard the R/V G. W. Pierce II. The specimen was fixed in 10\% formalin and later transferred to $70 \%$ ethanol for storage in the collections of the National Museum of Natural History (Smithsonian Institution). The specimen, which was damaged (part of carapace torn, most of antenna and distal parts of antennular flagella missing, second, fourth, and fifth pairs of legs missing) was partially dissected and illustrated using both stereoscope and compound microscope with camera lucida attachments.

\section{Systematics}

Family Thomassiniidae de Saint Laurent, 1979

\section{Crosniera Kensley and Heard, 1991}

\section{Crosniera wennerae sp. nov.}

Figures 1-3

Material examined. HOLOTYPE. USNM 174403, non-ovigerous female, total length $20 \mathrm{~mm}$, off North Carolina, USA, $33^{\circ} 00.97^{\prime} \mathrm{N}, 77^{\circ} 20.20^{\prime} \mathrm{W}, 318 \mathrm{~m}$, Texas Instruments/Minerals Management Service Station 1F, 10 February 1977.

Diagnosis. Female. Rostrum acute. Eyes poorly developed, each with two ommatidia and some pigment, lobes subacute distally. Maxilliped 2 and 3 each with well-developed exopod, extending beyond articulation of merus and carpus. Maxilliped 3 merus inner margin smooth. Telson without lateral spines. Uropodal margins smooth, endopod without spine on lateral margins.

Description. Female holotype.

Rostrum acutely tipped, not reaching beyond eyes. Carapace $6 \mathrm{~mm}$ in length, without mid-dorsal keel; linea thalassinica relatively short, extending posteriorly less than $1 / 3$ length of carapace, vertical row of six setae in antennal region of anterior carapace, three outer-most setae longest and plumose; cervical groove barely evident. Abdominal segment 2 longer than all others, with medial and anterior ventrolateral margins lightly fringed with setae, posteroventral margin with dense cluster of setae; abdominal segments 3-5 each with cluster of setae near ventrolateral margin just past mid-length; segment 6 posterelateral margins each with cluster of three long, simple setae extending to mid-region of telson. Telson dorsal surface smooth with a pair of proximal shallow lobes on lateral margins, with 7-8 long simple dorsal setae at 1/3 length; posterior margin broadly rounded and fringed with plumose setae, with two groups of 3 long submarginal simple setae near each distolateral margin.

Eyestalks stout, with blunt tips, dorsally rounded and flattened ventrally; eyes each with two ommatidia and some defuse pigmentation. Antenna 1 damaged, inner flagellum missing; peduncle article 3 reaching slightly beyond distal margin of antenna 2 article 4; scaphocerite reduced to small scale. Antenna 2 damaged, first 4 articles present.

Upper lip sparsely setose. Mandible incisor process strongly dentate, with 7-8 irregular teeth; shallow molar process with 3 teeth (two on distal inner margin and one on mid-inner margin; palp broad, strongly developed, distal article length about equal to that of articles 1 and 2 combined, distal half densely setose, with mix of simple and setulate spiniform setae. Maxilla 1 proximal endite with inner margin armed with row of setulate or pectinate, spiniform setae some becoming longer and bearing bidentate tips on proximal half of endite; distal endite with inner margin bearing row of stout spiniform conical setae; exopod with two articles, cluster of four setae on proximal margin of article 2, article 2 with long (subequal to article 2) curved spini 


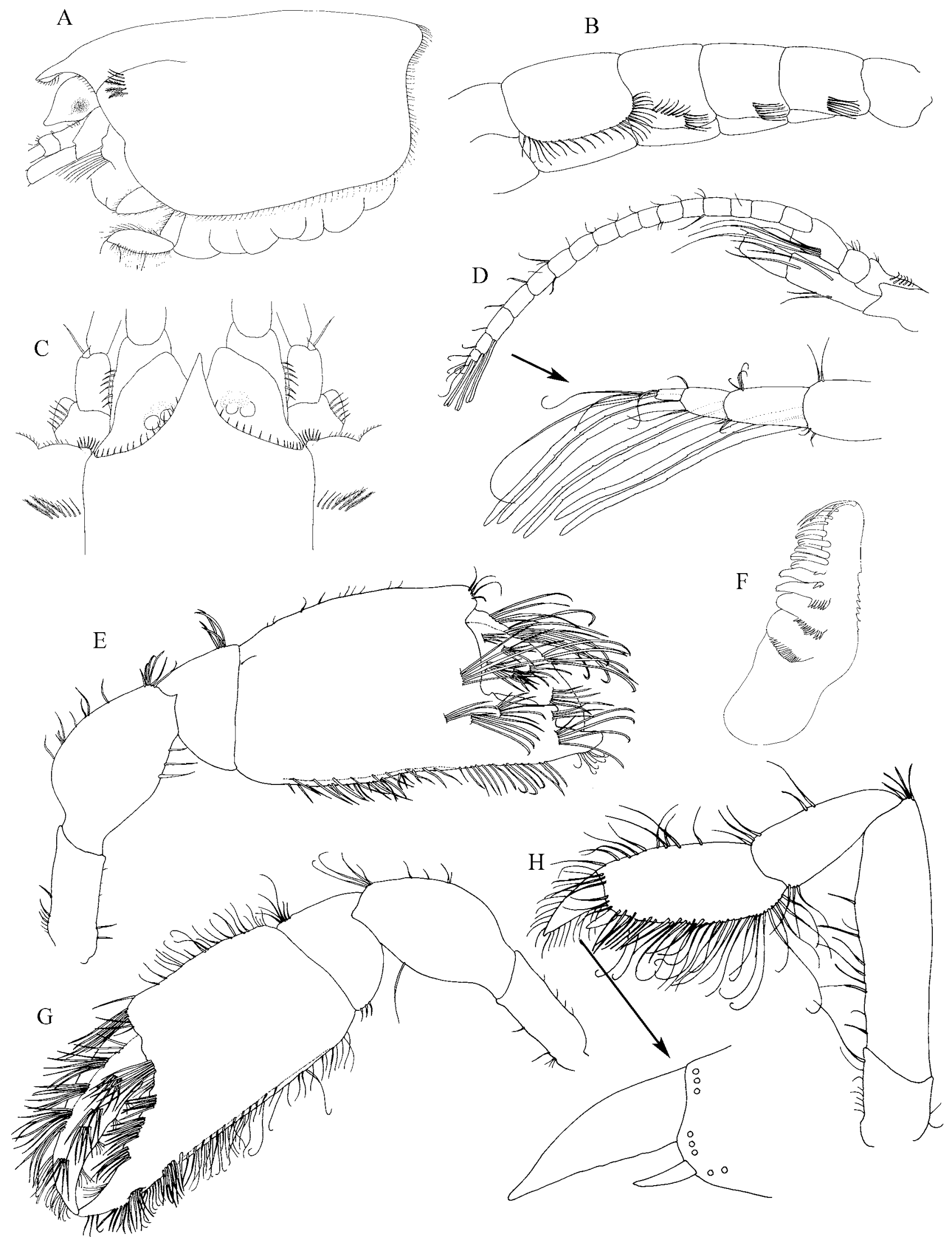

FIGURE 1. Crosniera wennerae sp. nov., female holotype, USNM 174403, TL 20 mm: A, lateral view of carapace; B, lateral view of abdomen showing segments $1-6$; $\mathrm{C}$, dorsal view of anterior carapace; $\mathrm{D}$, antenna 1; E, major chela (right); F, gastric mill; G, minor chela (left); H, pereopod 3 with enlargement of propodus tip. 


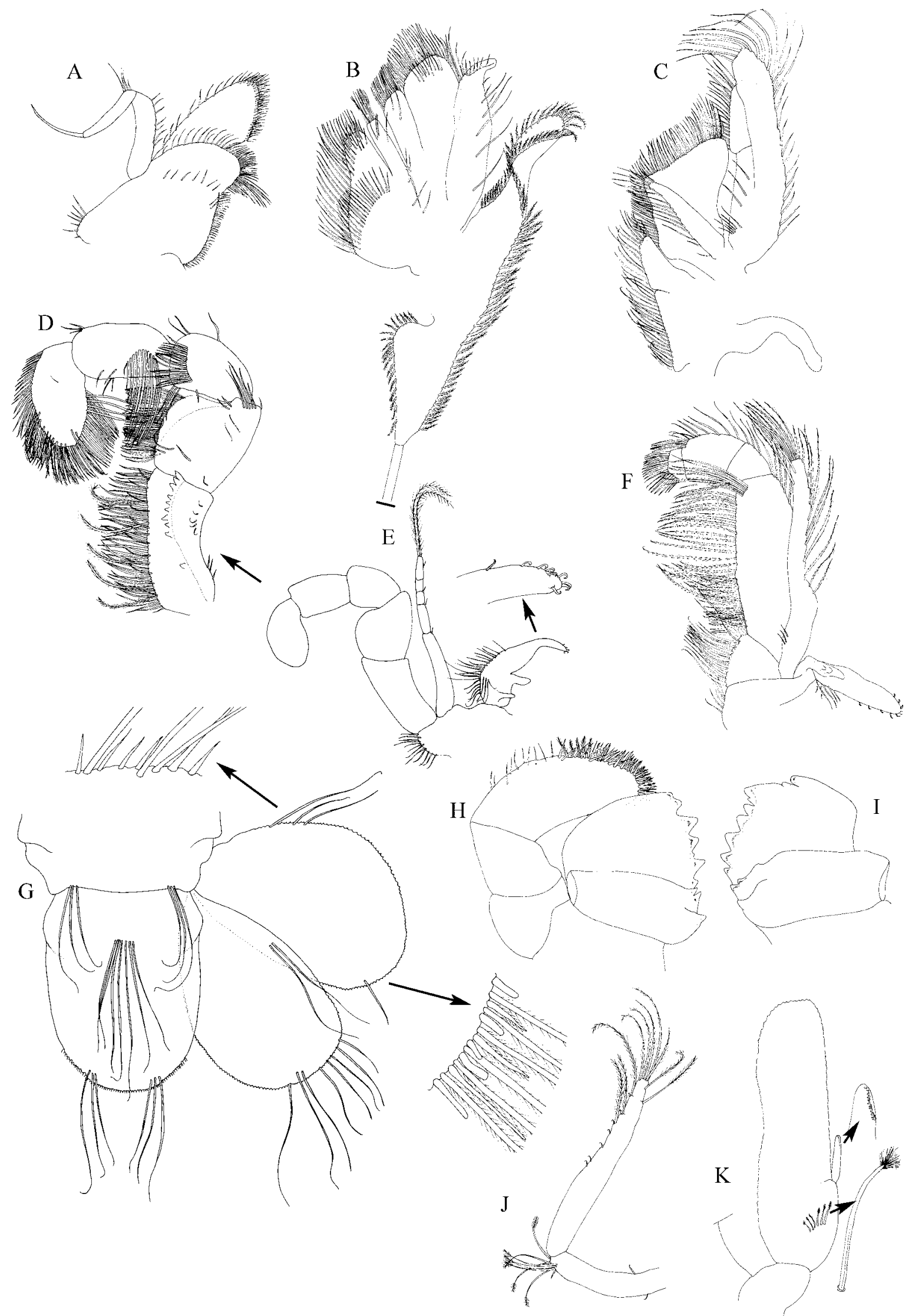

FIGURE 2. Crosniera wennerae sp. nov., female holotype, USNM 174403, TL 20 mm: A, maxilla 1; B, maxilla 2; C, maxilliped 1; D, enlargement of endopod of maxilliped 3; E, maxilliped 3; F, maxilliped 2; G, sixth abdominal segment with telson and uropods with enlargement of setation of exopod; $\mathrm{H}$, right mandible; I, left mandible (palp missing); J, pleopod 1; K, pleopod 5 (exopod missing). 




FIGURE 3. Crosniera wennerae sp. nov., female holotype, USNM 174403, TL 20 mm: branchial structures. A, single arthrobranch (third thoracomere); B, reduced podobranch (sixth thoracomere); C, two arthrobranchs (seventh thoracomere); D, epipod with detail of hooked setae at tip (sixth thoracomere); E, reduced epipod (seventh thoracomere).

form seta. Maxilla 2 endopod not tapering, tip blunt, curved laterally, extending slightly past distal-most endite and anterior tip of scaphognathite; scaphognathite well-developed, posterior lobe with distinctive long, terminal seta extending well into branchial chamber. Maxilliped 1 exopod lacking articulated palp; endopod not extending past distal endite; distal endite with distal margin straight, widest distally; proximal endite weakly bilobed; epipod damaged, distal lobe missing, represented only by narrow proximal lobe. Maxilliped 2 endopod with merus about twice combined length of carpus, propodus, and dactylus; exopod uniarticulate, well-developed, setose, extending just beyond distal end of merus of endopod; epipod and small podobranch present, epipod with several hooked setae along margin of distal half, with cluster of long simple setae present proximally. Maxilliped 3 endopod setose, ischium about twice as long as wide, inner face with row of 10 spines ( 9 in distal half of article and 1 in proximal half); merus globular, longer than carpus, about equal in length to propodus; dactylus rounded distally, paddle-shape, less than twice as long as wide; exopod extending well past articulation of merus and carpus, with five articles, first article slightly longer than combined length of last four, distal article with two long, setulose terminal setae; epipod tapering distally, with two podobranchs present, proximal outer margin with numerous simple setae, tip armed with several hooked setae.

Gastric mill strongly developed; lateral ossicles with grinding processes lobate proximally becoming spiniform distally, first two processes lobate with rounded tips and having inner margins densely spinose; next two processes attenuate with dentate tips, with inner margins bearing six spines and a tridentate spine, tips of next few setae grading from bidentate to deeply bifurcate, distal most 3-4 setae simple with curved acute tips. 
Pereopod 1 chelae dissimilar; right (major) chela more robust; its fixed finger bearing strong blunt subdistal tooth and small proximal tooth on cutting edge near articulation with movable finger; minor chela (left) fixed finger with single relatively small tooth midway along cutting edge. Pereopod 2 missing. Pereopod 3 with propodus about twice as long as wide, distal margin armed with single well-developed, spiniform seta. Pereopods 4, 5 and 6 missing.

Pleopod 1 uniramus, peduncle shorter than ramus, with cluster of seven long brush-tipped setae on outer distal margin; ramus with several small hooked setae along outer margin (similar to those on epipod of maxilliped 1), with 10 distal and subdistal plumose setae, presence of two apparently fused distal articles indicated. Pleopod 5 damaged, exopod missing, endopod about 3.5 times as long as wide, appendix interna with 15 small coupling hooks, with a row of 6 brushed-tipped setae on posterior face in between appendix interna and articulation with basal article.

Uropodal exopod length slightly more than 1.5 times width, broadly rounded, not bilobed, lateral margins fringed with plumose setae, short attenuated "cone setae" interspersed with fringing setae along outer mid-lateral margin, extending distally and merging with short, blunt tipped, spiniform setae, becoming less numerous medially; blunt spiniform setae extending nearly to inner distal margin; 3 or 4 long thin simple seta present on proximal lateral margin and 1 on subdistal margin; endopod length about 1.7 times width, with fringing row of plumose setae along distal half, with 2 long simple setae near proximal lateral margin and 7 or 8 long simple setae on subdistal and distal margin.

Branchial formula as in Table 1.

Etymology. This species is named for Elizabeth L. Wenner, of the South Carolina Department of Natural Resources, in recognition of her many contributions to crustacean biology and to the understanding of the ecology and faunal biodiversity of the South Atlantic Bight.

Table 1. Branchial formula for Crosniera wennerae. Epipod/podobranch on maxillipeds 2 and 3 (thoracomeres $2 \& 3$ ), epipods on thoracomers 4-7 (reduced or rudimentary $[=\mathrm{r}]$ on thoracomere 7). Single (1) arthrobranch on thoracomere 3, two (2) arthrobranchs on 4-7 becoming larger posteriorly.

\begin{tabular}{lllllllll}
\hline Thoracomere & 1 & 2 & 3 & 4 & 5 & 6 & 7 & 8 \\
Epipods & & + & + & + & + & + & + & $\mathrm{r}$ \\
Podobranchs & - & $\mathrm{r}$ & $\mathrm{r}$ & $\mathrm{r}$ & $\mathrm{r}$ & $\mathrm{r}$ & - & - \\
Arthrobranchs & - & $?$ & 1 & 2 & 2 & 2 & 2 & - \\
\hline
\end{tabular}

Distribution and Habitat. Crosniera wennerae sp. nov. is presently known from only the type locality in soft substratum on the upper continental slope $(318 \mathrm{~m})$ in the northern part of the South Atlantic Bight.

Remarks. Crosniera wennerae sp. nov. appears to have closer affinities with the western Pacific $C$. corindon than with the type species, C. minima, the only other member of the genus currently known from the western Atlantic.

Crosniera wennerae sp. nov. and $C$. corindon both lack a spine on the lateral margin of the uropodal endopod, but differ in a variety of characters including the lengths of the exopods on maxillipeds 2 and 3 (much longer in C. wennerae sp. nov.) and the setation patterns on the carapace, uropods, and telson. C. wennerae sp. nov. is readily distinguished from C. minima by several characters including (1) the shape and dentition of the first chelipeds, (2) smooth margin of the uropodal endopod, (3) shape and setation of the uropods and telson. The following key distinguishes the nominal species of the genus Crosniera. 


\section{Key to the nominal species of Crosniera Kensley and Heard, 1991}

1. Distolateral margin of uropodal endopod with spine......

- Distolateral margin of uropodal endopod smooth (lacking spine)

2. Lateral margins of telson with one or two blunt or weakly developed spines. Pereopod 1 ischium without distinct row of spines Crosniera minima (Rathbun, 1901)

- Lateral margin of telson with a pair of distinct, acutely tipped spines. Pereopod 1 ischium with distinct row of spines Crosniera panie Poore, 1997

3. Third maxilliped inner margin of merus rounded, lacking spine. Maxillipeds 2 and 3 with long exopods (extending beyond articulation of merus and carpus).

- Third maxilliped inner margin of merus armed with a spine. Maxillipeds 2 and 3 with short exopods (not extending beyond articulation of merus and carpus)

4. Eyes rounded distally. Third maxilliped with strong spine on distal inner margin and another smaller spine at mid-length of inner margin of merus. Uropodal endopod twice as long as wide, with small spine on median carina. Crosniera dayrati Ngoc-Ho, 2005

- Eyes acute distally. Third maxilliped with only a single small spine on distal inner margin of merus. Uropodal endopod less than twice as long as wide, lacking spine on median carina. Crosniera corindon Poore, 1997

\section{Discussion}

The known distribution for species of Crosniera can be divided into two general geographical clusters, the New World group in the northern hemisphere and the Southwest Pacific group in the southern hemisphere (see Figure 4). Including Poore's (1997) two formally undescribed species, the New World group consists of two species from the northwestern Atlantic and one from the northeastern Pacific; the Southwest Pacific group contains species from Polynesia, Indonesia, and New Caledonia (see Table 2).

TABLE 2. Reported locality and depth records for species of Crosniera Kensley and Heard, 1991

\begin{tabular}{|c|c|c|}
\hline Species & Locality & Depth (m) \\
\hline C. corindon Poore, 1997 & Indonesia $\left(0^{\circ} 14.9^{\prime} \mathrm{S}, 117^{\circ} 51.7^{\prime} \mathrm{E}\right)$ & 150 \\
\hline C. dayrati Ngoc-Ho, 2005 & French Polynesia (Marquesas Island) & $283-448$ \\
\hline C. minima (Rathbun, 1901) type) & Puerto Rico (Mayaguez Harbor);Alabama, USA; Venezuela & 294-315 \\
\hline C. panie Poore, 1997 & New Caledonia $\left(20^{\circ} 33.25^{\prime} \mathrm{S}, 164^{\circ} 49.3^{\prime} \mathrm{E}\right)$ & 40 \\
\hline C. wennerae Heard \& King, 2007 & US East Coast $\left(33^{\circ} 00.97^{\prime} \mathrm{N}, 77^{\circ} 20.20^{\prime} \mathrm{W}\right)$ & 318 \\
\hline Crosniera sp. 1 (of Poore, 1997) & Indonesia $\left(04^{\circ} 38.5^{\prime} \mathrm{N}, 119^{\circ} 49.43^{\prime} \mathrm{E}\right)$ & 2570 \\
\hline Crosniera sp. 2 (of Poore, 1997) & Mexico (Angeles Bay, Gulf of California) & 4 \\
\hline
\end{tabular}

The known depth range for the genus is 4-2570 $\mathrm{m}$ (Table 2); however, as pointed out by Poore (1997), the identification of Crosniera sp. 1, which was collected from $2570 \mathrm{~m}$, is tentative because all the pereopods were missing (the presence of a single spiniform seta on the propodus of the third pereopod is a pivotal family character). The remaining records for the genus are from near shore, continental shelf, and upper continental slope habitats (4-448 m).

At this time it cannot be determined if the three New World species and those from the southwestern Pacific represent disjunct, relict populations or if the lack of records for the genus from other regions (i.e., 
northwestern and southeastern Pacific, southwestern and eastern Atlantic) is an artifact of sampling. Because of apparent paucity of sampling in many regions of the world's oceans, especially on the outer continental shelf and continental slope, the latter may be the case.

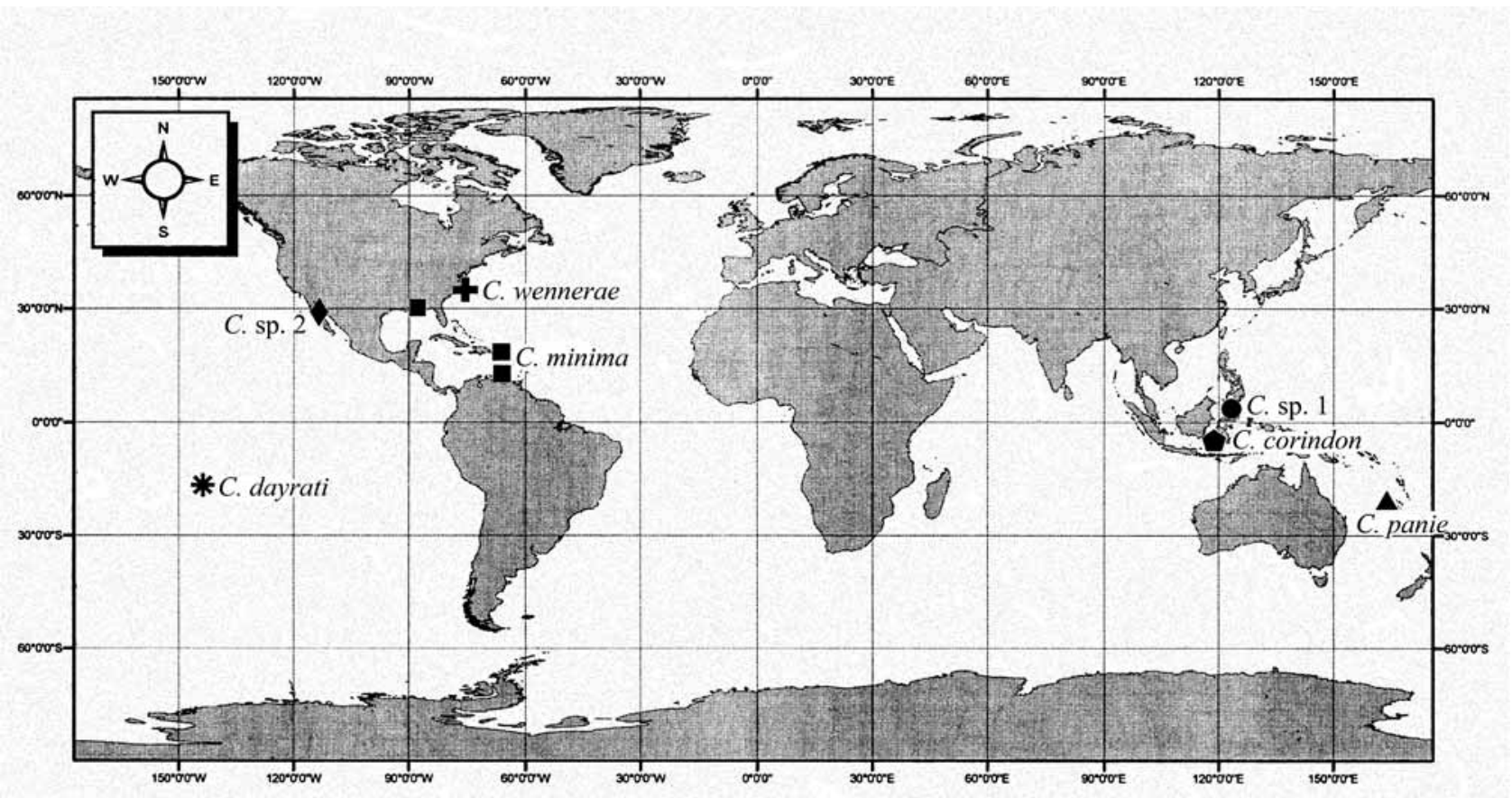

FIGURE 4. The distributions of the known species of Crosniera Kensley and Heard (including species 1 and 2 of Poore (1997).

\section{Acknowledgments}

We wish to thank Gary C. B. Poore (Museum Victoria, Australia) and Darryl L. Felder (University of Louisiana at Lafayette) for their assistance with thalassinidean gill morphology. We also thank David Knott (SCDNR) for his constructive comments and suggestions regarding the manuscript. T. Chad Walter and Cheryl Bright from the Invertebrate Zoology Department of the National Museum of Natural History (Smithsonian) arranged loans for much of the material studied. We are grateful to Brent Thoma for his helpful suggestions and comments during the initial part of this study. We also express our appreciation to the associate editor, Joe Goy and to the anonymous reviewers for their constructive comments and suggestions. This study was funded through a NOAA National Marine Fisheries Service grant to the Southeastern Regional Taxonomic Center (NA05NMF4721145). This document is Contribution No. 622 of the Marine Resources Division, South Carolina Department of Natural Resources.

\section{References}

Kensely, B. and R. W. Heard (1991) An examination of the shrimp family Callinideidae (Crustacea: Decapoda: Thalassinidea). Proceedings of the Biological Society of Washington, 104, 493-537.

Manning R. and D. L. Felder (1991) Revision of the American Callianassidae (Crustacea: Decapoda: Thalassinidea). Proceedings of the Biological Society of Washington, 104, 764-792.

Ngoc-Ho, N. (2005) Thalassinidea (Crustacea, Decapoda) from French Polynesia. Zoosytema, 27 (1), 47-48.

Poore, G. C. B. (1994) A phylogeny of the families of Thalassinidea (Crustacea: Decapoda) with keys to families and genera. Memoirs of Museum Victoria, 54, 79-120. 
Poore, G. C. B. (1997) A review of the thalassinidean families Callianideidae Kossmann, Micheleidae Sakai, and Thomassiniidae de Saint Laurent (Crustacea, Decapoda) with descriptions of fifteen new species. Zoosytema, 19(2-3), 345-420.

Rathbun, M. J. (1901) The Brachyura and Macrura of Porto Rico. Bulletin of the United States Fisheries Commission $1900,20(2), 1-127,129-137$.

Saint Laurent, M. de. (1979) Sur la classification et la phylogénie des thalasinides: définitions de la superfamille des Axioidea, de las sous-famille des Thomassiniinae et de deux genres nouveaux (Crustacea Deacpoda). Comptes Rendus Hebdomadaires de Séance de l'Académie des Sciences, Paris, 288, 1995-1397. 
